\title{
Distribution of Potato spindle tuber viroid in Reproductive Organs of Petunia During Its Developmental Stages
}

\author{
Yosuke Matsushita and Shinya Tsuda
}

First author: NARO Institute of Floricultural Science, 2-1 Fujimoto, Tsukuba 305-8519, Japan; and second author: NARO Agricultural

Research Center, Tsukuba, Ibaraki 305-8666, Japan.

Accepted for publication 22 February 2014.

\begin{abstract}
Matsushita, Y., and Tsuda, S. 2014. Distribution of Potato spindle tuber viroid in reproductive organs of petunia during its developmental stages. Phytopathology 104:964-969.

Embryo infection is important for efficient seed transmission of viroids. To identify the major pattern of seed transmission of viroids, we used in situ hybridization to histochemically analyze the distribution of Potato spindle tuber viroid (PSTVd) in each developmental stage of petunia (flowering to mature seed stages). In floral organs, PSTVd was

present in the reproductive tissues of infected female $\times$ infected male and infected female $\times$ healthy male but not of healthy female $\times$ infected male before embryogenesis. After pollination, PSTVd was detected in the developed embryo and endosperm in all three crosses. These findings indicate that PSTVd is indirectly delivered to the embryo through ovule or pollen during the development of reproductive tissues before embryogenesis but not directly through maternal tissues as cell-to-cell movement during embryogenesis.
\end{abstract}

Approximately 18 to $20 \%$ of described plant viruses are seed transmitted $(16,26)$. Seed transmission of numerous viruses is attributed to viral infection of the embryo directly during embryogenesis or indirectly through infection of the reproductive tissues (ovule, megaspore mother cell, and pollen mother cell) before embryogenesis $(5,16)$. There are some reports of indirect embryo invasion, following the observation of virus in the megaspore mother cell and egg or in pollen mother cells and pollen $(6,15,35,37)$. Because the embryo is separated physically from maternal tissues by a callose layer that prevents virus movement through plasmodesmata between cells, the virus must invade the embryo indirectly through reproductive tissues before the plasmodesmata disappear and callose barriers develop (23). These findings indicate that timing during the developmental stages of the reproductive organ is important for virus invasion of the seed embryo.

Not only viruses but also viroids are seed and pollen transmitted $(5,16,23)$. Viroids are the smallest and simplest of the plant pathogens, consisting of a single-stranded circular, naked RNA genome from 246 to 401 nucleotides (nt) in length, which lacks any protein-coding sequences $(9,12,34)$. However, histochemical information on seed infections by viroids is lacking (26). Therefore, it is unclear whether viroids are seed transmitted by direct or indirect embryo invasion during embryogenesis.

There are some reports of seed transmission of viroids; for example, Potato spindle tuber viroid (PSTVd) (18,19,27), Apple scar skin viroid (17), Avocado sunblotch viroid $(1,33)$, Chrysanthemum stunt viroid (CSVd) (7), Coleus blumei viroid (28), Grapevine yellow speckle viroid (32), Pepper chat fruit viroid (31), and Tomato apical stunt viroid (2). It is well known that PSTVd is transmitted at a high frequency by contaminated seed of tomato and potato $(3,13,18,19,27)$. Indeed, PSTVd is present in the ovule and placenta in the flower-opening stage of tomato (22).

Corresponding author: S. Tsuda; E-mail address: shinyat@ affrc.go.jp

http://dx.doi.org/10.1094/PHYTO-10-13-0294-R

(c) 2014 The American Phytopathological Society
However, little or nothing is known about the determinants of successful seed transmission of PSTVd. It is desirable to clarify the timing of embryo invasion by identifying the distribution patterns of PSTVd in tissues during the developmental stages of petunia (flowering to mature seed stages). Accordingly, we used in situ hybridization to observe the patterns of PSTVd in shoot apical meristems (SAMs), floral organs, ovaries after fertilization, and mature seed in each developmental stage of infected petunia $($ Petunia $\times$ hybrida). We discuss the possible routes of seed infection on the basis of the temporal changes in these patterns. This is the first report to show, histochemically, the distribution patterns of viroids in reproductive organs of petunia during its developmental stages (flowering to mature seed stages).

\section{MATERIALS AND METHODS}

Viroid isolate, plant materials, and its cultivation. PSTVd (358 nt) (21), isolated from diseased tomato plants found in Fukushima Prefecture, Japan, was employed for this study. This viroid had a genome sequence identical to that of the Cape gooseberry strain (GenBank accession number EU862231) (30). Petunia (Petunia $\times$ hybrida 'Kuripia') plants were mechanically inoculated with PSTVd into carborundum-dusted leaves, as described by Matsushita et al. (21). Healthy and inoculated plants were cultivated in a growth chamber maintained under a temperature regime of $27^{\circ} \mathrm{C}$ (day) and $25^{\circ} \mathrm{C}$ (night) and a cycle of 16 and $8 \mathrm{~h}$ of light and darkness, respectively. PSTVd-inoculated petunia plants were tested for viroid infection by reverse-transcription polymerase chain reaction (RT-PCR) for leaflets collected from the uppermost leaf of each plant 2 months after inoculation, as described by Matsushita et al. (21).

Pollination and determination of seed transmission. To distinguish between seed and pollen transmission of PSTVd, infected petunia and healthy plants were used as pollen recipients or donors. Pollination was performed in three combinations: healthy female $\times$ infected male $(\mathrm{H} \times \mathrm{I})$, infected female $\times$ healthy male $(\mathrm{I} \times \mathrm{H})$, and infected female $\times$ infected male $(\mathrm{I} \times \mathrm{I})$. To avoid contact transmission of the viroid, disposable paper or gloves 
were used when handling flower parts. After maturation, seed were collected and dried at room temperature for 1 week. Seed transmission of PSTVd was determined by testing seedlings grown from seed sown in the soil. PSTVd infection of the seedlings was confirmed by RT-PCR, as described above, followed by sequence analysis of the RT-PCR products, as described by Matsushita et al. (20). To confirm the presence of PSTVd in seedlings, 'Rutgers' tomato seedlings were mechanically inoculated with sap from infected seedlings grown from seed.

Determination of horizontal transmission by infected pollen. To determine whether PSTVd is transmitted from pollen to mother plants during fertilization, 24 healthy petunia plants were pollinated with pollen collected from PSTVd-infected petunia plants. This experiment was conducted three times, and three flowers on each plant were pollinated. PSTVd infection was determined by RT-PCR of leaflets collected from the uppermost leaf of each plant 3 months after pollination, as described by Matsushita et al. (21). RT-PCR was performed three times on each sample.

Hybridization probes. Digoxigenin (DIG)-labeled minusstrand PSTVd riboprobes were prepared by in vitro transcription using SalI-linearized p94PSV (22), which covers the full-length nucleotide sequence of PSTVd (accession number EU862231) as a template in a DIG-11-UTP NTP mix (Roche Diagnostics

TABLE 1. Seed transmission of Potato spindle tuber viroid (PSTVd) in infected petunia plants

\begin{tabular}{lccc}
\hline & \multicolumn{2}{c}{ Number of germinated seedlings } & \\
\cline { 2 - 3 } Cross $^{\mathrm{a}}$ & Infected & Total & Infection rate $(\%)$ \\
\hline $\mathrm{I} \times \mathrm{H}$ & 15 & 29 & 51.7 \\
$\mathrm{I} \times \mathrm{I}$ & 18 & 23 & 78.0 \\
$\mathrm{H} \times \mathrm{I}$ & 10 & 18 & 55.0 \\
\hline
\end{tabular}

a Type of cross (female $\times$ male); $\mathrm{I}=$ infected and $\mathrm{H}=$ healthy.

${ }^{b}$ PSTVd was detected by both mechanical inoculation into tomato and reverse transcription polymerase chain reaction.
GmbH, Mannheim, Germany) and T7 RNA polymerase (Roche Diagnostics $\mathrm{GmbH}$ ), according to the manufacturer's protocol.

Tissue processing for in situ hybridization. Sampled tissues were processed by the Sainte-Marie method (25), with some modifications. Apical stems; flower buds (length $=0.5$ to $10 \mathrm{~mm}$ ); ovaries obtained from $\mathrm{H} \times \mathrm{I}, \mathrm{I} \times \mathrm{H}$, and $\mathrm{I} \times \mathrm{I}$ crosses in various developmental stages after fertilization; and seed were fixed in formaldehyde, dehydrated, embedded in paraffin, and sectioned to 10 to $12 \mu \mathrm{m}$, and in situ hybridization was performed according to Matsushita et al. (22), with some modifications. When the color had sufficiently developed, the sections were mounted and examined under a microscope. Observations were confirmed by the examination of serial sections. At least six plants were used for in situ hybridization to ensure reproducibility.

\section{RESULTS}

Verification of contaminants for seed transmission of PSTVd, either female or male. To determine which parent is a source of viroid contamination for seed transmission, vertical transmission tests using PSTVd-infected petunia were performed with crossing to either parent or both. Seed transmission for each cross is shown in Table 1 . In $\mathrm{I} \times \mathrm{H}$ and $\mathrm{I} \times \mathrm{I}$, in both of which crosses the female was the contaminant, these rates were 51.7 and $78 \%$, respectively. When pollen derived from an infected male was used for crossing to a healthy female $(\mathrm{H} \times \mathrm{I})$, the seed transmission rate was $55 \%$. The seed transmission rate in each combination was high, which was similar to that previously described for potato and tomato $(19,27)$.

Changes in PSTVd distribution in SAMs and floral organs during the developmental stages. PSTVd was detected in leaf primordia but not in SAMs (Fig. 1A). This observation was confirmed by the examination of serial longitudinal sections. No hybridization signal was observed in noninfected plants, which were used as a negative control (Fig. 1B). Positive signals from PSTVd were detected in all floral organs sectioned over serial

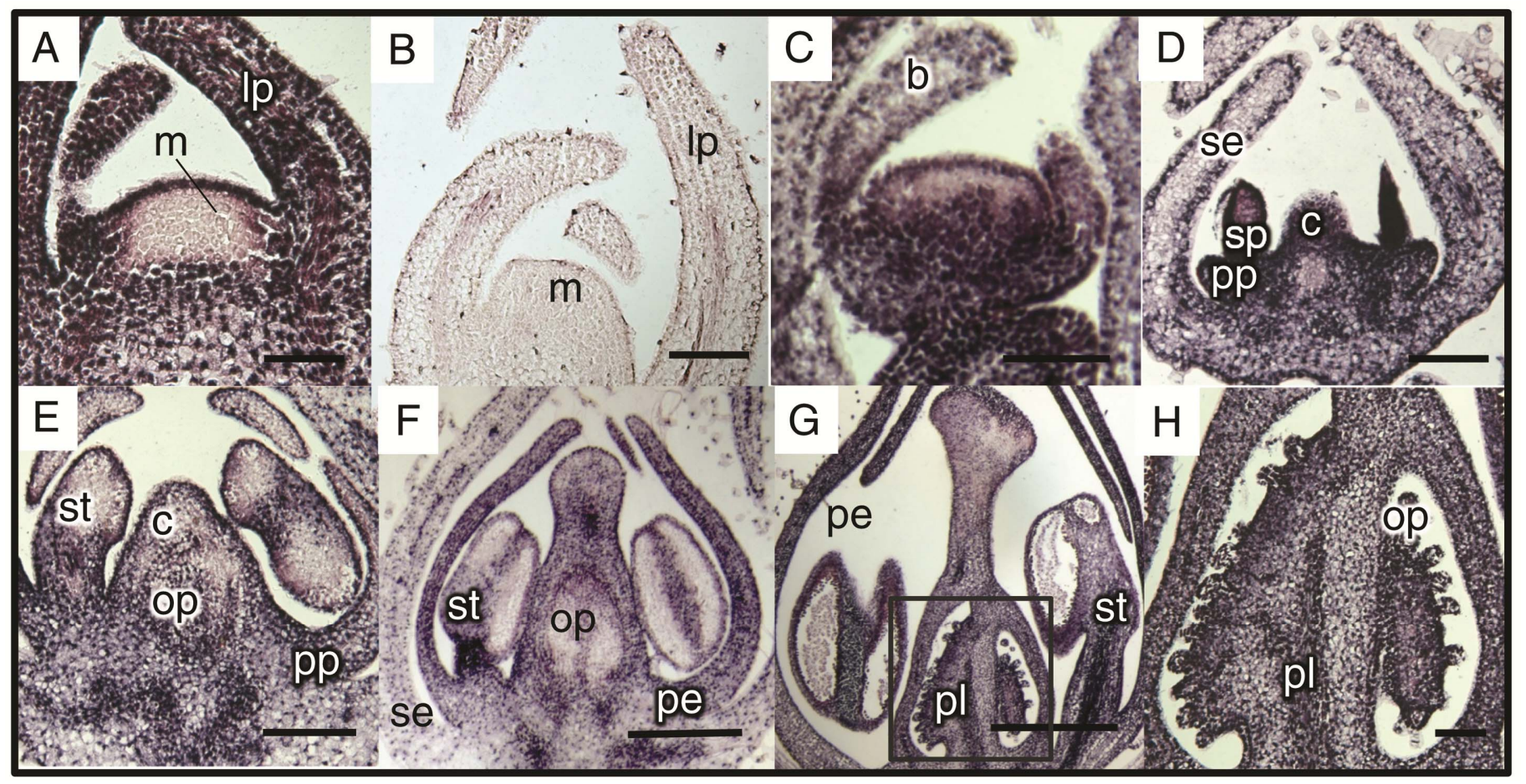

Fig. 1. Changes in the distribution of Potato spindle tuber viroid (PSTVd) in the shoot apical meristem and flower buds ranging from the floral shoot through the developmental stages of petunia. A, Longitudinal section of the shoot meristem of a PSTVd-infected petunia. B, Longitudinal section of the shoot meristem of a healthy petunia. $\mathbf{C}$ to $\mathbf{G}$, Longitudinal section of a PSTVd-infected flower bud. H, High magnification of the ovule primordium and placenta showing open square in G. Abbreviations: $\mathrm{b}=$ bract; $\mathrm{c}=$ carpel; $\mathrm{lp}=$ leaf primordium; $\mathrm{m}=$ meristem; op = ovule primordium; $\mathrm{pl}=\mathrm{placenta} ; \mathrm{pe}=\mathrm{petal} ; \mathrm{pp}=$ petal primordium; $\mathrm{se}=$ sepal; st = stamen; sp = stamen primordium. Bars indicate $20 \mu \mathrm{m}$ in $\mathrm{A}, \mathrm{B}$, and $\mathrm{H} ; 50 \mu \mathrm{m}$ in $\mathrm{C}$ to $\mathrm{F}$; and $100 \mu \mathrm{m}$ in $\mathrm{G}$. 
developmental stages. In the floral shoot stage, PSTVd was present, except in a few cell layers that resembled SAMs (Fig. 1C). In the following stage, the viroid was detected in carpel, petal primordia, stamen primordia, and sepal but not in ovary primordia (Fig. 1C to F). Although PSTVd was absent from the ovule primordium (Fig. 1F), it was observed in the early ovules in the succeeding stage (Fig. 1G). PSTVd was not detected in the stamen primordium and pollen grain (Fig. 1F to G). PSTVd was present in the ovary wall, placenta, and ovules of PSTVd-infected petunia plants (Fig. 1H). These observations were confirmed by the observation of serial sections.

Time course analysis of PSTVd distribution in ovules during the developmental stages leading to seed formation. The developmental period of seed formation in ovary parts of $\mathrm{I} \times \mathrm{I}$ PSTVd-infected petunia before and after fertilization was divided into seven stages for the observation of changes in PSTVd distribution. Before fertilization as the first stage or probably just after fertilization as the second stage, PSTVd was already distributed in integuments and parenchyma following the placenta in the early stage of embryogenesis (Fig. 2A and B). The embryo sac located at the center of a premature seed showed no viroid signal. The seed epidermis displayed an orange autocolor. In the third stage (the ovules 5 to 10 days after pollination), PSTVd was clearly observed in the endothelium surrounding the embryo sac but the signals had decreased from the inner parts of parenchyma toward the endothelium (Fig. 2C). In the fourth stage, PSTVd was observed in the developing endosperm and embryo, together with the endothelium enveloping them, the signals had completely disappeared from the parenchyma (Fig. 2D). The endosperm enveloped with endothelium showing the PSTVd signals was gradually swelling and the embryo was growing, indicating specific signals in the fifth stage, although the parenchyma was likely to be slowly crushed between epidermis and endothelium (Fig. 2E). In the sixth stage, the endosperm was fully expanded in the seed epidermis but the PSTVd signals in the cell nuclei had weakened. In contrast, the embryo was fully developed, strengthening the color of the signal. Parenchyma tissue had finally degenerated (Fig. 2F). In mature seed, the PSTVd signals were detected only in embryo tissue and not in SAM of the embryo in the seventh stage. Specific signals in endosperm tissue had been completely lost (Fig. 2G). This series of observations describes the distribution of PSTVd in developing seed of petunia. No hybridization signal was observed in uninfected healthy controls (Fig. 2H).

PSTVd distribution in ovules originating in infected female plants. To assess the distribution of PSTVd from infected female plants to the embryo, we observed it through the developmental period of seed formation in PSTVd-infected petunia fertilized with pollen from healthy plants in the $\mathrm{I} \times \mathrm{H}$ cross. In the ovule just after fertilization, a zygote arising from an egg fused with a sperm cell from a healthy plant was infected with PSTVd (Fig. 3A). The PSTVd signals were observed along the vascular bundle tissue from placental tissue to parenchyma cells in the developing seed (Fig. 3B). From the late globular (Fig. 3C) to the early heart embryo stage (Fig. 3D) in maturing seed, PSTVd distributions were similar to those in the $\mathrm{I} \times \mathrm{I}$ cross (Fig. 2).

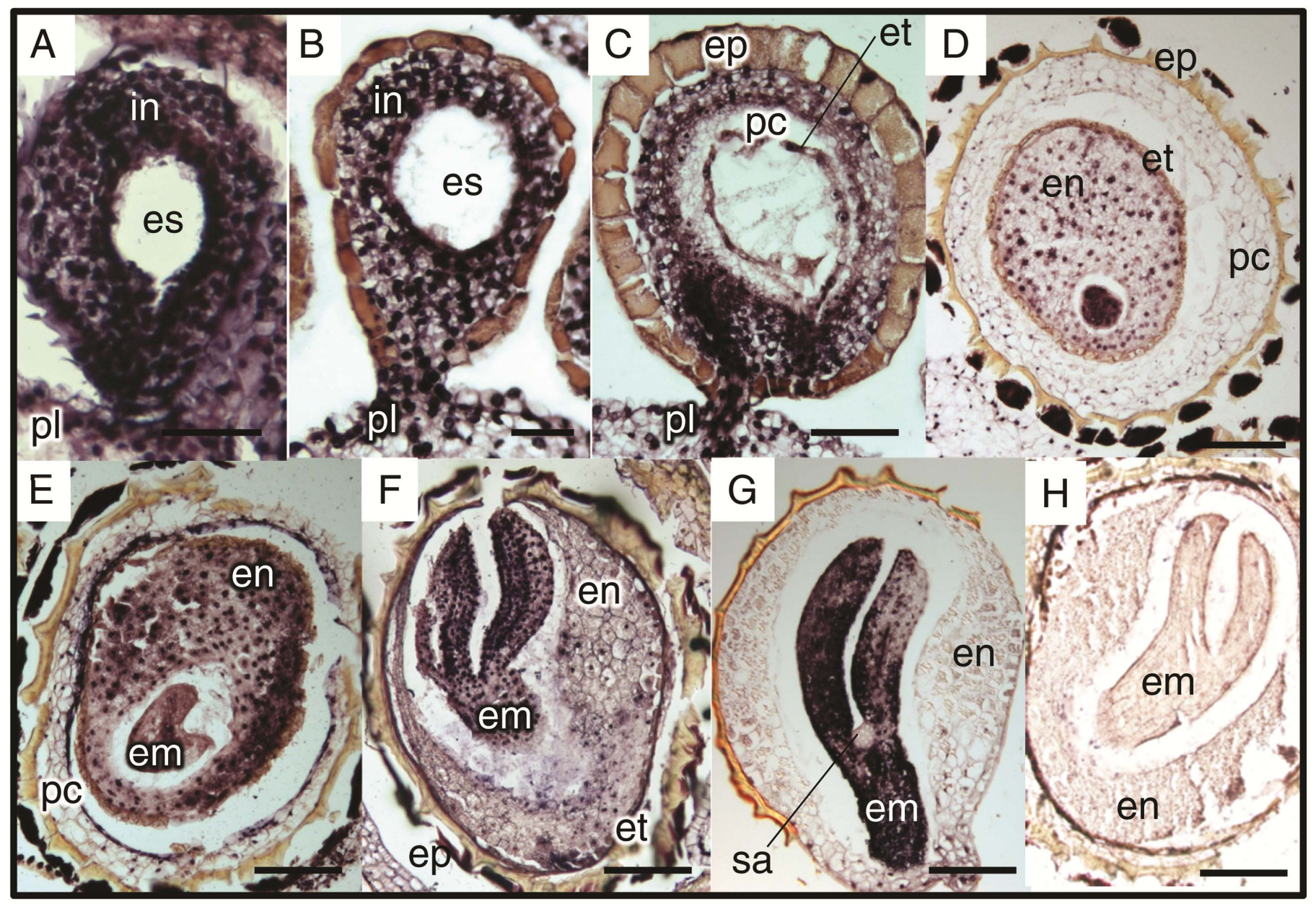

Fig. 2. Changes in the distribution of Potato spindle tuber viroid (PSTVd) in flowers of an infected petunia A, before and $\mathbf{B}$ to G, after fertilization in tissues ranging from the ovule to the mature seed. $\mathbf{H}$, Longitudinal sections of a healthy mature seed. Abbreviations: es $=$ embryo sac; em = embryo; en = endosperm; ep = epidermis of the seed coat; et = endothelium; in = integuments; $\mathrm{pl}=$ placenta; $\mathrm{pc}=$ parenchyma cells; $\mathrm{sa}=$ shoot apical meristem. Bars indicate $100 \mu \mathrm{m}$ in $\mathrm{A}$ and $\mathrm{B}$ and $200 \mu \mathrm{m}$ in $\mathrm{C}$ to $\mathrm{H}$. 
PSTVd distribution in ovules following pollen transmission. Ovary parts of petunia infected by the $\mathrm{H} \times$ I route were observed over a developmental period of seed formation before and after fertilization. Before fertilization and probably just after fertilization, PSTVd was not present in the ovule of the healthy mother plant (Fig. 4A). In the stage after fertilization, PSTVd derived from pollen was still not detected in the premature seed (Fig. 4B). In the next stage, PSTVd was clearly present in the early heart embryo stage, and a few PSTVd signals were confirmed in endo- sperm cells (Fig. 4C). According to seed development, the PSTVd signals had been spreading to endosperm cells (Fig. 4D to F). During seed development following fertilization, PSTVd from pollen did not invade parenchyma cells and the placenta, which is maternal tissue (Fig. 4B to F). Moreover, no PSTVd could be detected in leaves of any of the 72 female petunia flowers pollinated with PSTVd-infected pollen over the cultivation for 3 months. The presence of pollen-derived PSTVd in the embryo supports the high seed transmission rates shown in Table 1.

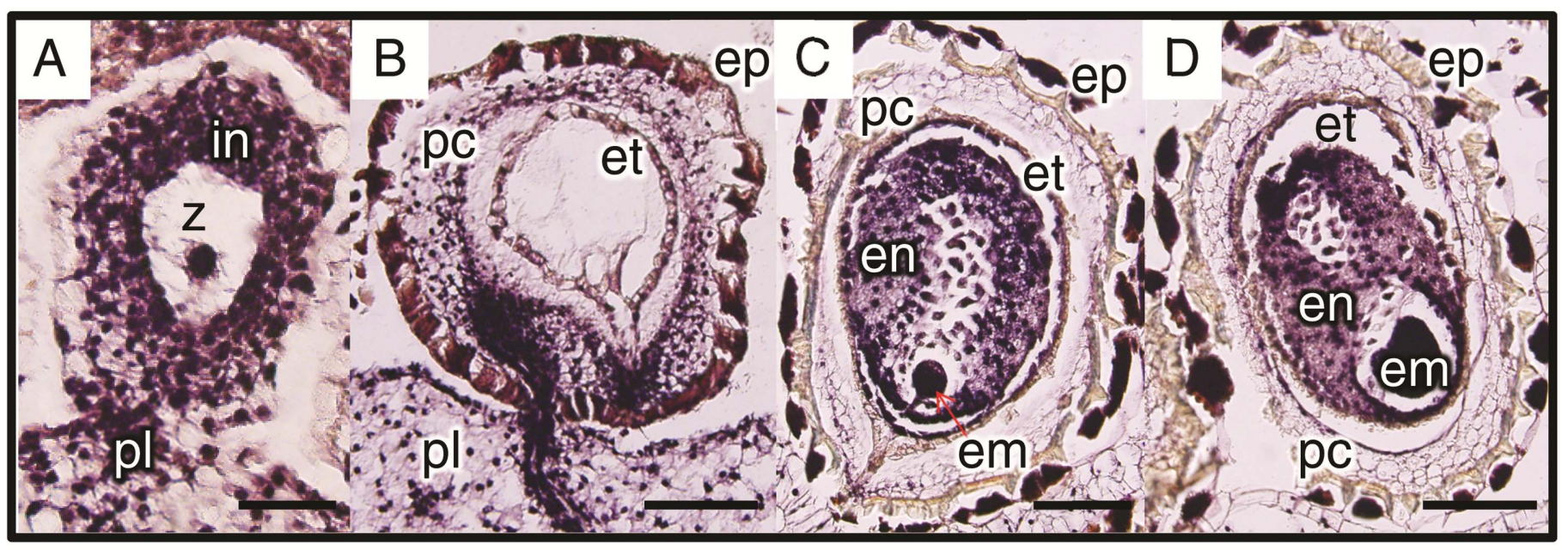

Fig. 3. A to D, Changes in the distribution of Potato spindle tuber viroid (PSTVd) in the ovule of a PSTVd-infected petunia pollinated with pollen from healthy plants after fertilization in tissues ranging from the ovule to the seed. Abbreviations: em $=$ embryo; en $=$ endosperm; ep $=$ epidermis of the seed coat; et $=$ endothelium; in = integuments; $\mathrm{pl}=$ placenta; $\mathrm{pc}=$ parenchyma cells; $\mathrm{z}=$ zygote. Bars indicate $100 \mu \mathrm{m}$ in $\mathrm{A}$ and $200 \mu \mathrm{m}$ in $\mathrm{B}$ to $\mathrm{D}$.

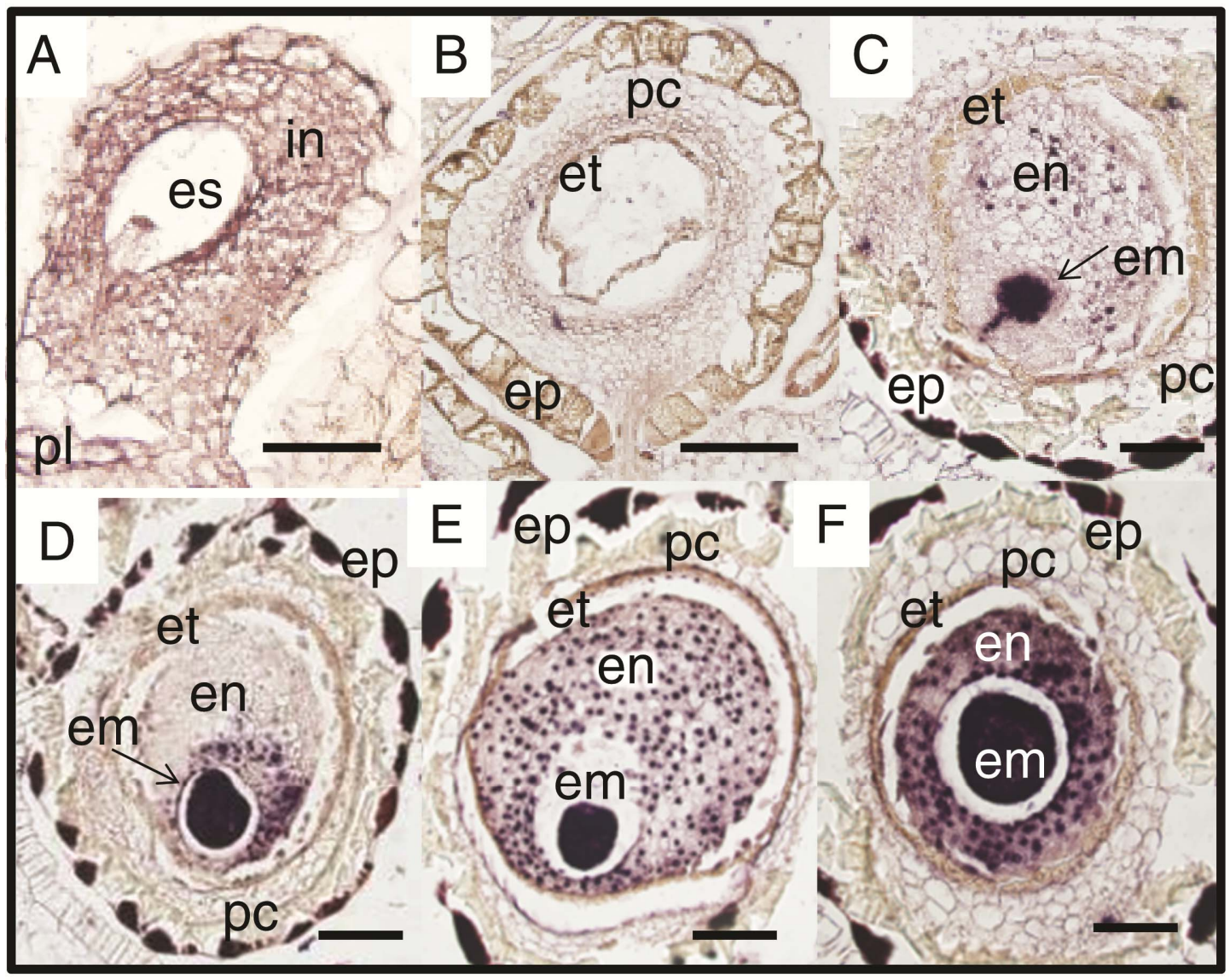

Fig. 4. Changes in the distribution of Potato spindle tuber viroid (PSTVd) in the ovule of a healthy petunia A, before and $\mathbf{B}$ to F, after pollination with pollen from PSTVd-infected plants after fertilization in tissues ranging from the ovule to the mature seed. Abbreviations: es $=$ embryo sac; em $=\mathrm{embryo}$; en $=\mathrm{endosperm}$; ep $=$ epidermis of the seed coat; et $=$ endothelium; in = integuments; $\mathrm{pl}=$ placenta; $\mathrm{pc}=$ parenchyma cells. Bars indicate $100 \mu \mathrm{m}$ in $\mathrm{A}$ and $\mathrm{B}$ and $200 \mu \mathrm{m}$ in $\mathrm{C}$ to $\mathrm{F}$. 


\section{DISCUSSION}

In seed transmission of plant viruses, there are two systems for invading the embryo, one direct and the other indirect. In the case of viroid invasion, it was still unclear whether the embryo may directly become infected from maternal tissues during embryogenesis or indirectly through ovule or pollen infection of reproductive tissues before embryogenesis. Our observation that PSTVd infected reproductive tissues such as the ovule before embryogenesis reveals that PSTVd can invade the embryo through pollen (i.e., seed transmission of PSTVd occurs by indirect embryo invasion through the infected embryo sac or pollen).

According to the progress of flower development, the cell-tocell connections between reproductive organs change drastically during microsporogenesis and microgametogenesis (26). For example, the female archesporium and megaspore mother cell have plasmodesmatal connections with the nuclear cells. The functional megaspore and two- and four-nucleate embryo sacs have plasmodesmatal connections to the nucleus. However, the organized embryo sac wall completely lacks plasmodesmatal connections with the surrounding tissue at this time. In the organized embryo sac, the egg, synergids, and central cell are only partially surrounded by cell walls and are in contact only through the plasma membrane (26). Furthermore, the embryo is separated physically from the mother plant by a callose layer (23) and, therefore, because viroid intercellular trafficking occurs not through plasma membrane-mediated transport but, rather, through plasmodesmata (10), a viroid cannot directly infect the embryo. Thus, the viroid must invade the embryo indirectly through reproductive tissues before the plasmodesmata disappear and the callose barriers develop. Therefore, PSTVd must move into the egg cell in the embryo sac before the plasmodesmata between the embryo sac and placenta tissue have disappeared in the mature ovule stage.

The petunia integument, which differentiates into the seed coat, consists of an outer epidermis, an inner epidermis called the endothelium, and approximately six layers of parenchyma cells (8). The parenchyma cells and endothelium degenerate, resulting in one layer of parenchyma cells between the outer epidermis and the endosperm (8). Thus, with the degeneration of the parenchyma cells, PSTVd signals in the parenchyma cells disappeared upon disintegration of nuclei, because PSTVd accumulates in nuclei. In addition, the endosperm is rich in cytoplasm and storage products (8), and nuclear fragmentation in the endosperm cells occurs during endosperm programmed cell death $(4,36)$. This nuclear fragmentation might account for the disappearance of PSTVd in the endosperm cells.

Tissues in which PSTVd was absent were SAMs of the developing vegetative shoot and embryo in mature seed. At least, presumptive SAM tissue in which PSTVd was not present was observed in the heart-stage embryo (data not shown). However, it is unclear whether cells such as the egg cell and embryonic SAM in which PSTVd is absent are maintained from fertilization to embryogenesis. In the $\mathrm{I} \times \mathrm{I}$ cross, because both the egg cell in the embryo sac and the sperm cell in pollen were infected with PSTVd, the early embryo tissue arising from the fertilized egg fused with the sperm cell should also have been infected with PSTVd. Thus, SAMs in which PSTVd was not present would be generated from an infected egg cell during embryogenesis. Viroid-free plantlets have previously been obtained from infected plants by somatic embryogenesis (14). Thus, there may be a mechanism of impairment of embryogenesis in viroid-infected cells or the involvement of a defense mechanism, perhaps with accidental targeting, against invading viroid RNAs in SAM tissue. Moreover, it has recently been shown that PSTVd exclusion from SAMs is likely due to an RNA-silencing-based degradation mechanism (11). Thus, the mechanism of impairment or the involvement of a defense mechanism during embryogenesis may also be related to the RNA-silencing-based degradation mechanism involved in PSTVd exclusion from SAMs.

PSTVd was detected in pollen grains from PSTVd-infected potato by return polyacrylamide gel electrophoresis (29) and by RT-PCR in pollen of PSTVd-infected petunia (data not shown). It is possible that current in situ hybridization protocols are simply not sufficiently sensitive to detect very low levels of PSTVd in pollen. It was, however, observed that PSTVd was present in the early embryo after fertilization with pollen from PSTVd-infected petunia, indicating that pollen-derived PSTVd can invade the embryo sac through the pollen tube. Thus, these results show that PSTVd was present in the sperm cells of pollen derived from PSTVd-infected petunia. Five viroids in four genera are known to be pollen transmitted in one or more plant species (5), including PSTVd in tomato (27) and CSVd in chrysanthemum (7), with pollen transmission rates of 2 to $9 \%$ and 46.9 to $75.7 \%$, respectively. Given that pollen transmission of CSVd in chrysanthemum is high, this transmission may have occurred in the same manner as that in petunia, by seed transmission of PSTVd following invasion of the embryo through pollen.

There are some reports of horizontal transmission as well as vertical transmission of viroids by pollen $(13,17,19)$. However, after fertilization, PSTVd was not detected in any mother plant pollinated with pollen from PSTVd-infected petunia while the plants were continuously maintained in the greenhouse for 3 months (i.e., no horizontal transmission of PSTVd occurred in petunia). PSTVd spreads within tomato plants in a pattern similar to photoassimilate transport through the phloem (24). Zhu et al. (38) demonstrated that PSTVd is trafficked into sink but not source leaves during systemic movement, suggesting that viroid movement follows the pattern of photoassimilate. Given that the developing seed is sink tissue, it is plausible that PSTVd derived from pollen would not leak into female tissue. Furthermore, the embryo is separated physically from the mother plant by a callose layer (23); therefore, a mechanism is required to enable the viroids to move without a direct vascular connection or cellular contact, as mentioned above (5). Because viroids move through plasmodesmata (10), it would be difficult for PSTVd to move without direct vascular connection or cellular contact.

In the three types of crossing used in this study, some seed were not infected by PSTVd. Although PSTVd was present in all ovules of PSTVd infected-petunia plants before pollination and all integuments after pollination, a few embryos and endosperms were not infected with PSTVd (Table 1). Virus inactivation in the embryos during seed maturation has been reported $(16,26)$, although the mechanisms remain unknown. Embryos may also have mechanisms of viroid inactivation.

\section{ACKNOWLEDGMENTS}

We thank I. Fujisawa for useful comments on this study; and Y. Matsumura, Y. Narita, and J. Sato for maintaining the plants.

\section{LITERATURE CITED}

1. Allen, R. N., Palukaitis, P., and Symons, R. H. 1981. Purified Avocado sunblotch viroid causes disease in avocado seedlings. Australas. Plant Pathol. 10:31-32.

2. Antignus, Y., Lachman, O., and Pearlsman, M. 2007. Spread of Tomato apical stunt viroid (TASVd) in greenhouse tomato crops is associated with seed transmission and bumble bee activity. Plant Dis. 91:47-50.

3. Benson, A. P., and Singh, R. P. 1964. Seed transmission of potato spindle tuber virus in tomato. Am. Potato J. 41:294.

4. Berger, F. 1999. Endosperm development. Curr. Opin. Plant Biol. 2:28-32.

5. Card, S. D., Pearson, M. N., and Clover, G. R. 2007. Plant pathogens transmitted by pollen. Australas. Plant Pathol. 36:455-461.

6. Carroll, T. W., and Mayhew, D. E. 1976. Occurrence of virions in developing ovules and embryo sacs of barley in relation to the seed transmissibility of barley stripe mosaic virus. Can. J. Bot. 54:2497-2512. 
7. Chung, B. N., and Pak, H. S. 2008. Seed transmission of Chrysanthemum stunt viroid in chrysanthemum (Dendranthema grandiflorum) in Korea. Plant Pathol. J. 24:31-35.

8. Colombo, L., Franken, J., Van der Krol, A. R., Wittich, P. E., Dons, H. J., and Angenent, G. C. 1997. Downregulation of ovule-specific MADS box genes from petunia results in maternally controlled defects in seed development. Plant Cell 9:703-715.

9. Ding, B. 2009. The biology of viroid-host interactions. Annu. Rev. Phytopathol. 47:105-131.

10. Ding, B., Kwon, M. O., Hammond, R., and Owens, R. 1997. Cell-to-cell movement of Potato spindle tuber viroid. Plant J. 12:931-939.

11. Di Serio, F., De Alba, M. A-E., Navarro, B. Gisel, A., and Flores R. 2010. RNA-dependent RNA polymerase 6 delays accumulation and precludes meristem invasion of a viroid that replicates in the nucleus. J. Virol. 84:2477-2489.

12. Di Serio, F., and Flores R. 2008. Viroids: Molecular implements for dissecting RNA trafficking in plants. RNA Biol. 5:128-131.

13. Fernow, K. H., Peterson, L .C., and Plaisted, R. L. 1970. Spindle tuber virus in seeds and pollen of infected potato plants. Am. Potato J. 47:7580 .

14. Gambino, G., Navarro, B., Vallania, R., Gribaudo, I., and Di Serio, F. 2011. Somatic embryogenesis efficiently eliminates viroid infections from grapevines. Eur. J. Plant Pathol. 130:511-519.

15. Gaspar, J. O. Vega, J., Camargo, I. J. B., and Costa, A. S. 1984. An ultrastructural study of particle distribution during microsporogenesis in tomato plants infected with the Brazilian tobacco rattle virus. Can. J. Bot. 62:372-378.

16. Johansen, E., Edwards, M. C., and Hampton, R. O. 1994. Seed transmission of viruses: Current perspectives. Annu. Rev. Phytopathol. 32:363386.

17. Hadidi, A., Hansen, A. J., Parish, C. L., and Yang. X. 1991. Scar skin and dapple apple viroids are seed-borne and persistent in infected apple trees. Res. Virol. 142:289-296.

18. Hunter, D. E., Darling, H. M., and Beale, W. L. 1969. Seed transmission of potato spindle tuber virus. Am. Potato J. 46:247-250.

19. Kryczynski, S., Paduch-Cichal, E., and Skrzeczkowski, L. J. 1988. Transmission of three viroids through seed and pollen of tomato plants. J. Phytopathol. 121:51-57.

20. Matsushita, Y., Kanda, A., Usugi, T., and Tsuda, S. 2008. First report of a Tomato chlorotic dwarf viroid disease on tomato plants in Japan. J. Gen. Plant Pathol. 74:182-184.

21. Matsushita, Y., Usugi, T., and Tsuda, S. 2010. Development of a multiplex RT-PCR detection and identification system for Potato spindle tuber viroid and Tomato chlorotic dwarf viroid. Eur. J. Plant Pathol. 128:165-170.

22. Matsushita, Y., Usugi, T., and Tsuda, S. 2011. Distribution of tomato chlorotic dwarf viroid in floral organs of tomato. Eur. J. Plant Pathol. 130:441-447.

23. Mink, G. I. 1993. Pollen-and seed-transmitted viruses and viroids. Annu. Rev. Phytopathol. 31:375-402.

24. Palukaitis, P. 1987. Potato spindle tuber viroid: Investigation of the longdistance, intra-plant transport route. Virology 158:239-241.

25. Sainte-Marie, G. 1962. A paraffin embedding technique for studies employing immunofluorescence. J. Histochem. Cytochem. 10:250-256.

26. Singh, D., and Mathur, S. B. 2004. Histopathology of Seed-borne Infections. CRC Press, New York.

27. Singh, R. P. 1970. Seed transmission of potato spindle tuber virus in tomato and potato. Am. Potato J. 47:225-227.

28. Singh, R. P., Boucher, A., and Singh, A. 1991. High incidence of transmission and occurrence of a viroid in commercial seeds of Coleus in Canada. J. Plant Pathol. 13:202-211.

29. Singh, R. P., Boucher, A., and Somerville, T. H. 1992. Detection of potato spindle tuber viroid in the pollen and various parts of potato plant pollinated with viroid-infected pollen. Plant Dis. 76:951-953.

30. Verhoeven, J. T. J., Botermans, M., Roenhorst, J. W., Westerhof, J., and Meekes, E. T. M. 2009. First Report of Potato spindle tuber viroid in Cape Gooseberry (Physalis peruviana) from Turkey and Germany. Plant Dis. 93:316.

31. Verhoeven, J. T. J., Jansen, C. C. C., Roenhorst, J. W., Flores, R., and de la Pena, M. 2009. Pepper chat fruit viroid: Biological and molecular properties of a proposed new species of the genus Pospiviroid. Virus Res.144:209-214.

32. Wah, Y. F. W. C., and Symons, R. H. 1999. Transmission of viroids via grape seed. J. Phytopathol. 147:285-291.

33. Wallace, J. M., and Drake. R. J. 1962. A high rate of seed transmission of avocado sun-blotch virus from symptomless trees and the origin of sun trees. Phytopathology 52:237-241.

34. Wang, Y., and Ding, B. 2010. Viroids: Small probes for exploring the vast universe of RNA trafficking in plants. J. Intergr. Plant Biol. 52:28-39.

35. Wilcoxson, R. D., Johnson, L. E. B., and Frosheiser, F. I. 1975. Variation in the aggregation forms of alfalfa mosaic virus strains in different alfalfa organs. Phytopathology 65:1249-1254.

36. Wojciechowska, M., and Olszewska, M. J. 2003. Endosperm degradation during seed development of Echinocystis lobata (Cucurbitaceae) as a manifestation of programmed cell death (PCD) in plants. Folia Histochem. Cytobiol. 41:41-50.

37. Yang, A. F., and Hamilton, R. I. 1974. The mechanism of seed transmission of tobacco ringspot virus in soybean. Virology 62:26-37.

38. Zhu, Y., Green, L., Woo, Y.-M., Owens, R. A., and Ding, B. 2001. Cellular basis of Potato spindle tuber viroid systemic movement. Virology 279: 69-77. 